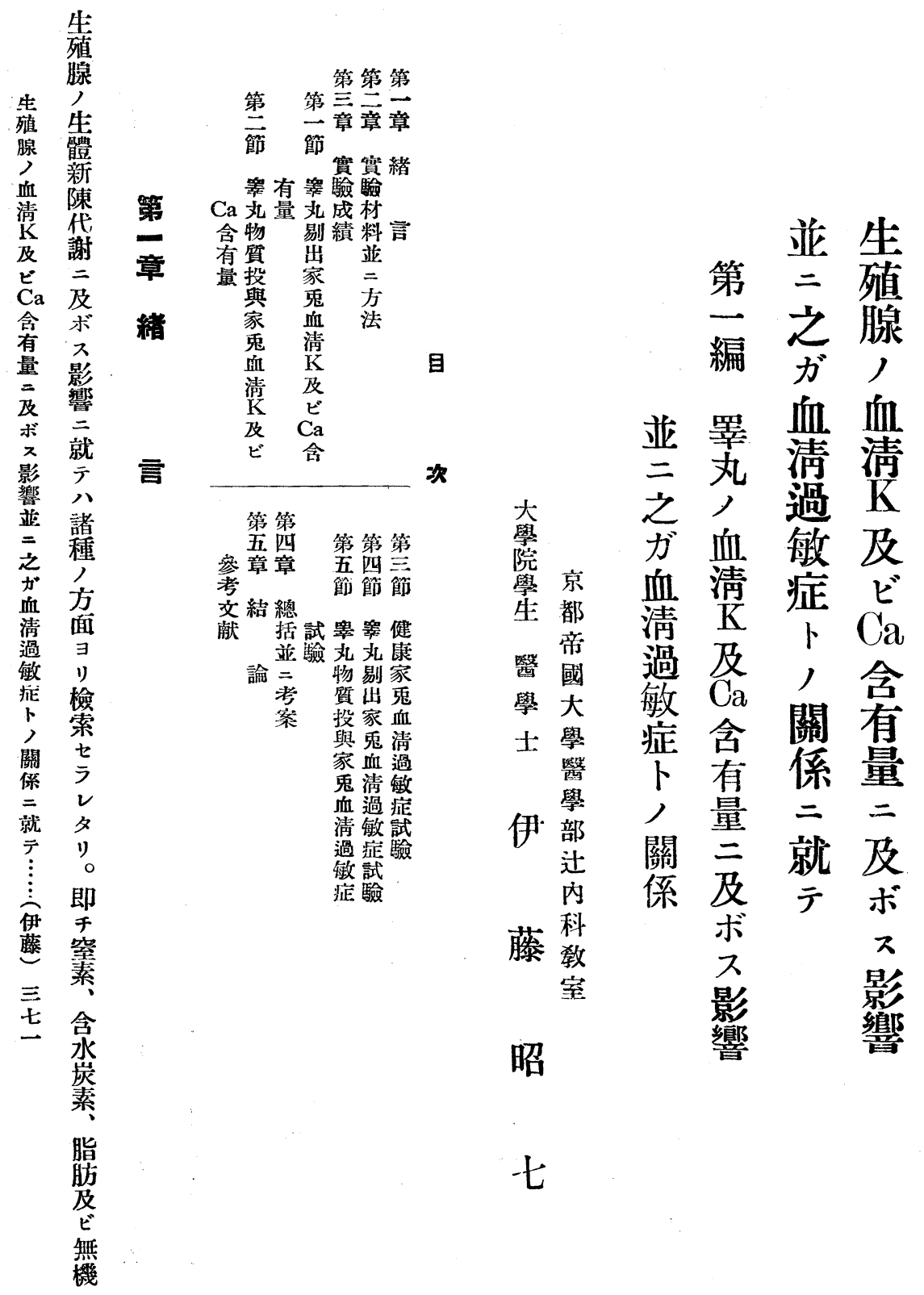




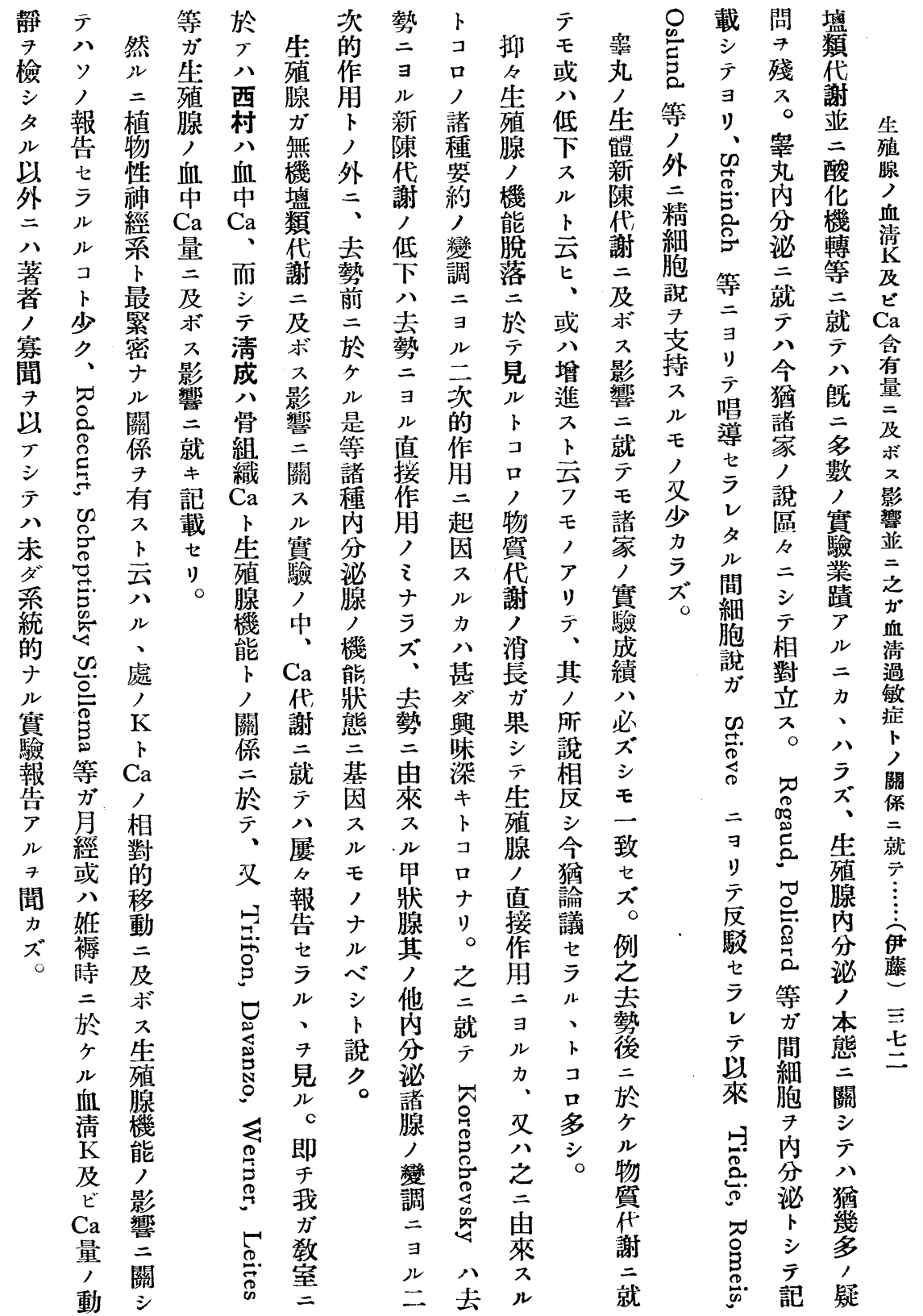




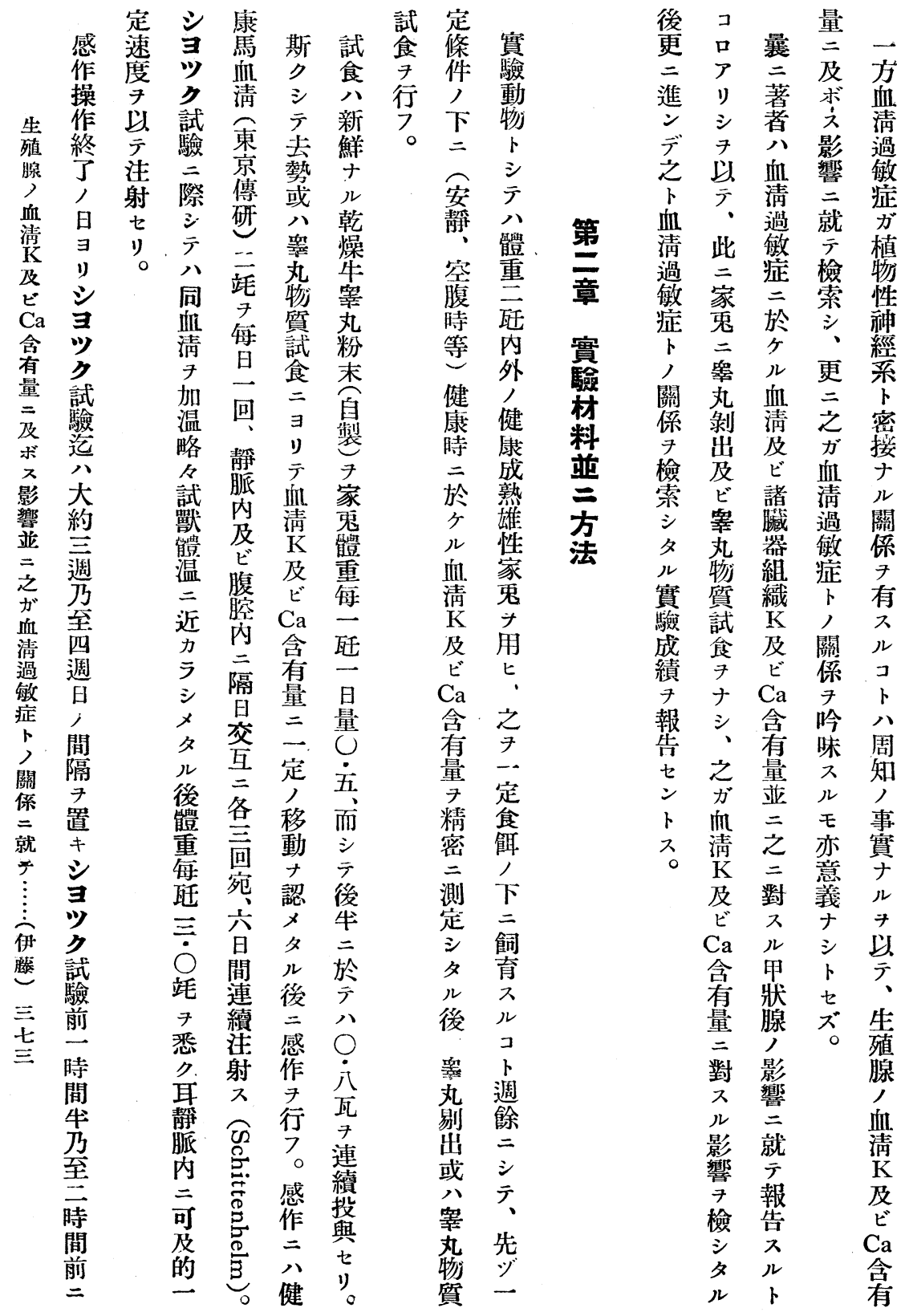




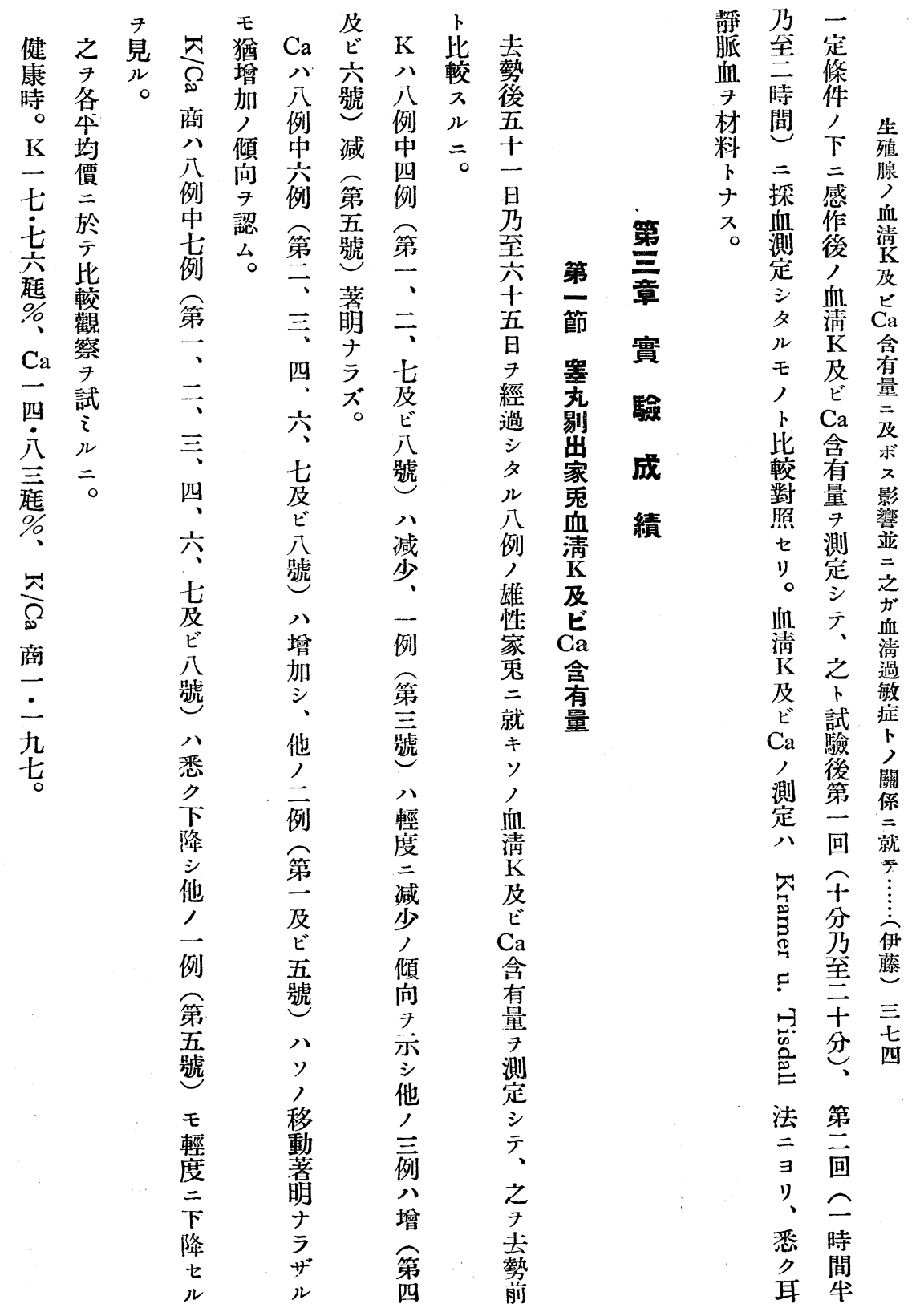


第一表 睪礼剔出家鬼

\begin{tabular}{|c|c|c|c|c|c|c|}
\hline 番號 & 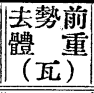 & $\begin{array}{l}\text { 去勢後德 } \\
\text { (再) } \\
\text { (重) }\end{array}$ & イオン & 健康時 & 去勢後 I & $\begin{array}{l}\text { 去勢後 II } \\
\text { (感作後) }\end{array}$ \\
\hline \multirow{3}{*}{1} & \multirow{3}{*}{1970} & \multirow{3}{*}{2060} & $\mathrm{~K}$ & 18.32 & 15.76 & 16.11 \\
\hline & & & $\mathrm{Ca}$ & 15.42 & 15.76 & 16.08 \\
\hline & & & $\mathrm{K} / \mathrm{Ca}$ & 1.194 & 1.0 & 1.0 \\
\hline \multirow{3}{*}{2} & \multirow{3}{*}{$19 \tilde{0}$} & \multirow{3}{*}{2150} & $\mathrm{~K}$ & 17.75 & 16.33 & 16.12 \\
\hline & & & $\mathrm{Ca}$ & 14.56 & 15.54 & 15.64 \\
\hline & & & $\mathrm{K} / \mathrm{Ca}$ & 1.219 & 1.05 & 1.016 \\
\hline \multirow{3}{*}{3} & \multirow{3}{*}{$19 t 0$} & \multirow{3}{*}{2170} & $\mathrm{~K}$ & 17.37 & 16.61 & 15.83 \\
\hline & & & $\mathrm{Ca}$ & 15.20 & 16.00 & 15.86 \\
\hline & & & $\mathrm{K} / \mathrm{Ca}$ & 1.142 & 1.038 & 1.0 \\
\hline \multirow{3}{*}{4} & \multirow{3}{*}{1990} & \multirow{3}{*}{2200} & $\mathrm{~K}$ & 20.21 & 20.59 & 17.87 \\
\hline & & & $\mathrm{Ca}$ & 14.66 & 16.10 & 14.88 \\
\hline & & & $\mathrm{K} / \mathrm{Ca}$ & 1.385 & 1.275 & 1.202 \\
\hline \multirow{3}{*}{5} & \multirow{3}{*}{1980} & \multirow{3}{*}{2190} & $\mathrm{~K}$ & 16.98 & 16.47 & 17.04 \\
\hline & & & $\mathrm{Ca}$ & 14.78 & 15.10 & 15.54 \\
\hline & & & $\mathrm{K} / \mathrm{Ca}$ & 1.149 & 1.09 & 1.096 \\
\hline \multirow{3}{*}{6} & \multirow{3}{*}{1900} & \multirow{3}{*}{2150} & $\mathrm{~K}$ & 17.04 & $17.4 t^{\circ}$ & 17.31 \\
\hline & & & $\mathrm{Ca}$ & 14.98 & 16.00 & 16.00 \\
\hline & & & $\mathrm{K} / \mathrm{Ca}$ & 1.139 & 1.09 & 1.07 \\
\hline \multirow{3}{*}{7} & \multirow{3}{*}{1960} & \multirow{3}{*}{2160} & $\mathrm{~K}$ & 17.83 & 14.48 & \\
\hline & & & $\mathrm{Ca}$ & 14.50 & 15.54 & \\
\hline & & & $\mathrm{K} / \mathrm{Ca}$ & 1.16 & 0.931 & \\
\hline \multirow{3}{*}{8} & \multirow{3}{*}{1990} & \multirow{3}{*}{2090} & $\mathrm{~K}$ & 16.62 & 14.91 & 18.60 \\
\hline & & & $\mathrm{Ca}$ & 14.56 & 15.10 & 15.06 \\
\hline & & & $\mathrm{K} / \mathrm{Ca}$ & 1.14 & 0.987 & 1.235 \\
\hline \multirow[t]{2}{*}{ 平 } & & & $\mathrm{K}$ & 17.76 & 16.58 & 16.93 \\
\hline & & & $\mathrm{Ca}$ & 14.83 & 15.64 & 15.58 \\
\hline 均 & & & $\mathrm{K} / \mathrm{Ca}$ & 1.197 & 1.059 & 1.088 \\
\hline
\end{tabular}

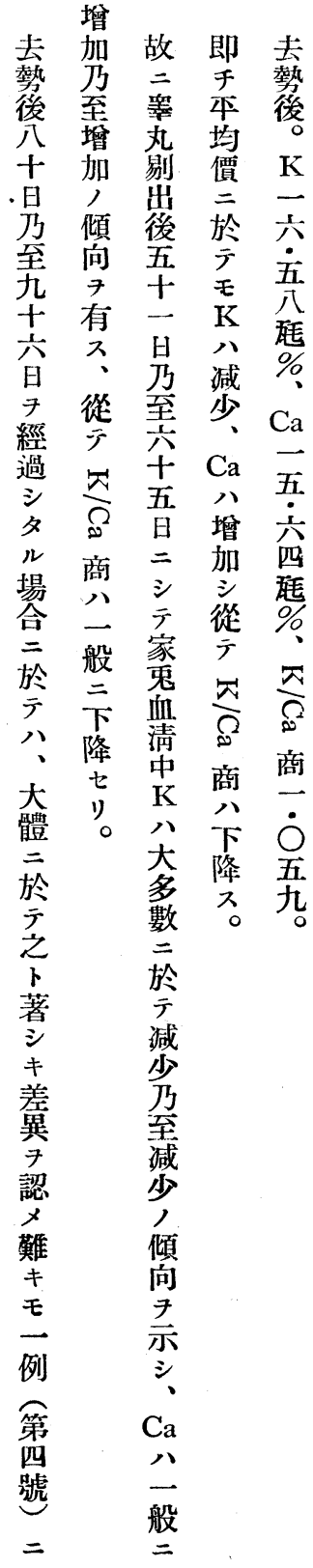




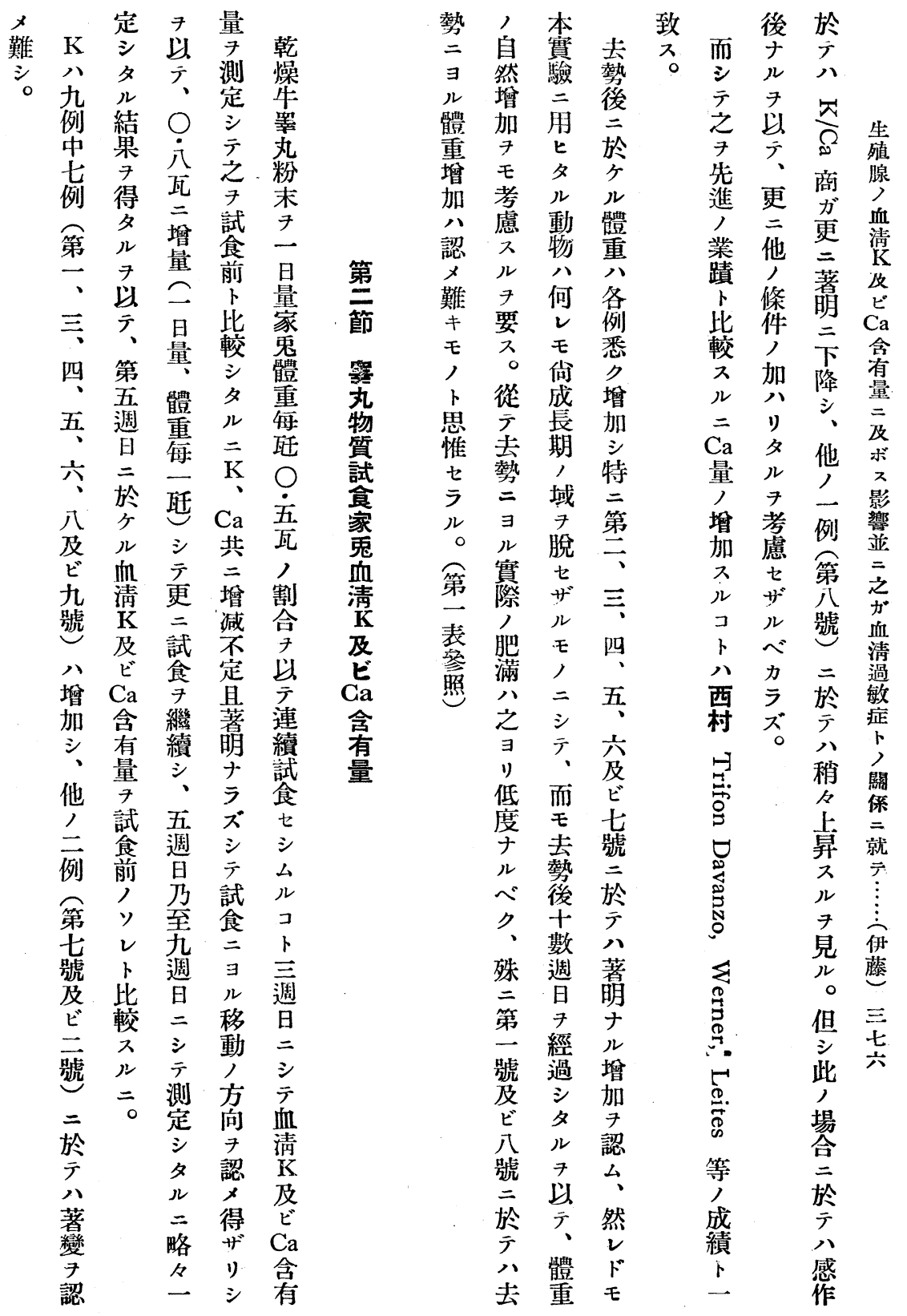


第二表 罪光物貿試食家鬼

\begin{tabular}{|c|c|c|c|c|c|c|}
\hline 番號 & 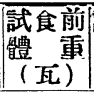 & 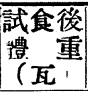 & 1オン & 健康時 & 試食後 I & $\begin{array}{l}\text { 試食後 II } \\
\text { (憝作後) }\end{array}$ \\
\hline \multirow{3}{*}{1} & \multirow{3}{*}{2200} & \multirow{3}{*}{2390} & $\mathrm{~K}$ & 18.13 & 20.87 & 18.69 \\
\hline & & & $\mathrm{Ca}$ & 15.14 & 15.45 & 15.10 \\
\hline & & & $\mathrm{K} / \mathrm{Ca}$ & 1.197 & 1.283 & 1.237 \\
\hline \multirow{3}{*}{2} & \multirow{3}{*}{2330} & \multirow{3}{*}{2350} & $\mathrm{~K}$ & 19.60 & 19.73 & 18.23 \\
\hline & & & $\mathrm{Ca}$ & 15.32 & $15: 33$ & 15.20 \\
\hline & & & $\mathrm{K} / \mathrm{Ca}$ & 1.279 & 1.282 & 1.20 \\
\hline \multirow{3}{*}{3} & \multirow{3}{*}{2080} & \multirow{3}{*}{2460} & $\mathrm{~K}$ & 15.86 & 19.02 & 19.13 \\
\hline & & & $\mathrm{Ca}$ & 15.00 & 15.36 & 15.40 \\
\hline & & & $\mathrm{K} / \mathrm{Ca}$ & 1.06 & 1.231 & 1.242 \\
\hline \multirow{3}{*}{4} & \multirow{3}{*}{2350} & \multirow{3}{*}{2580} & $\mathrm{~K}$ & 17.75 & 21.34 & 18.73 \\
\hline & & & $\mathrm{Ca}$ & 14.46 & 15.34 & 15.30 \\
\hline & & & $\mathrm{K} / \mathrm{Ca}$ & 1.227 & 1.236 & 1.224 \\
\hline \multirow{3}{*}{5} & \multirow{3}{*}{2120} & \multirow{3}{*}{2460} & $\mathrm{~K}$ & 16.76 & 18.34 & 17.82 \\
\hline & & & $\mathrm{Ca}$ & 14.24 & 14.88 & 14.66 \\
\hline & & & $\mathrm{K} / \mathrm{Ca}$ & 1.161 & 1.232 & 1.215 \\
\hline \multirow{3}{*}{6} & \multirow{3}{*}{2050} & \multirow{3}{*}{2070} & $\mathrm{~K}$ & 17.98 & 20.70 & 19.66 \\
\hline & & & $\mathrm{Ca}$ & 14.88 & 15.22 & 15.32 \\
\hline & & & $\mathrm{K} / \mathrm{Ca}$ & 1.208 & 1.36 & 1.283 \\
\hline \multirow{3}{*}{7} & \multirow{3}{*}{2000} & \multirow{3}{*}{2170} & $\mathrm{~K}$ & 18.60 & 19.104 & 20.02 \\
\hline & & & $\mathrm{Ca}$ & 15.21 & 15.66 & 15.66 \\
\hline & & & $\mathrm{K} / \mathrm{Ca}$ & 1.223 & 1.22 & 1.278 \\
\hline \multirow{3}{*}{8} & \multirow{3}{*}{1940} & \multirow{3}{*}{2200} & $\mathrm{~K}$ & 18.27 & 19.88 & 19.88 \\
\hline & & & $\mathrm{Ca}$ & 15.09 & 15.20 & 14.66 \\
\hline & & & $\mathrm{K} / \mathrm{Ca}$ & 1.21 & 1.308 & 1.356 \\
\hline \multirow{3}{*}{9} & \multirow{3}{*}{2110} & \multirow{3}{*}{2360} & $\mathrm{~K}$ & 17.68 & 19.54 & 19.24 \\
\hline & & & $\mathrm{Ca}$ & 14.56 & 14.93 & 14.44 \\
\hline & & & $\mathrm{K} / \mathrm{Ca}$ & 1.214 & 1.241 & 1.332 \\
\hline \multirow[t]{3}{*}{ 平 } & & & $\mathrm{K}$ & 17.85 & 19.83 & 19.04 \\
\hline & & & $\mathrm{Ca}$ & 14.88 & 15.27 & 15.09 \\
\hline & & & $\mathrm{K} / \mathrm{Ca}$ & 1.199 & 1.298 & 1.263 \\
\hline
\end{tabular}

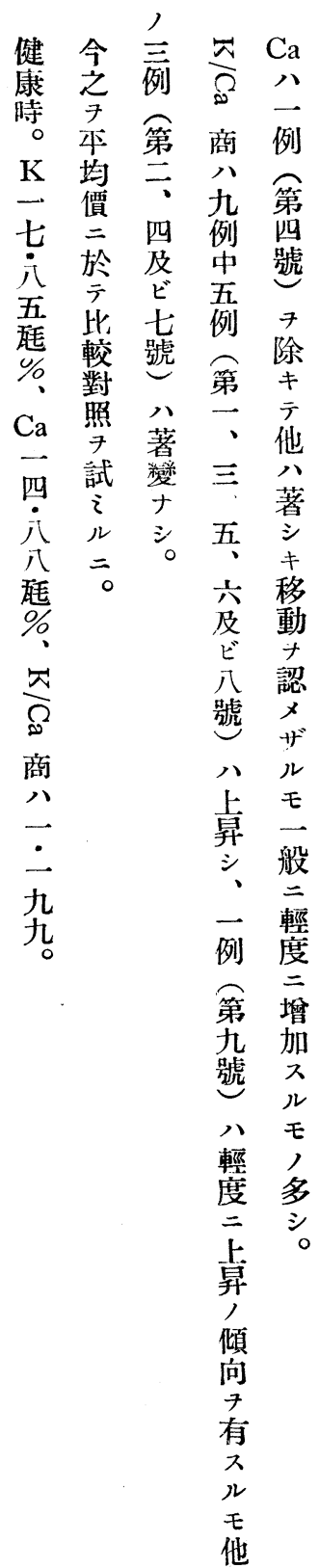




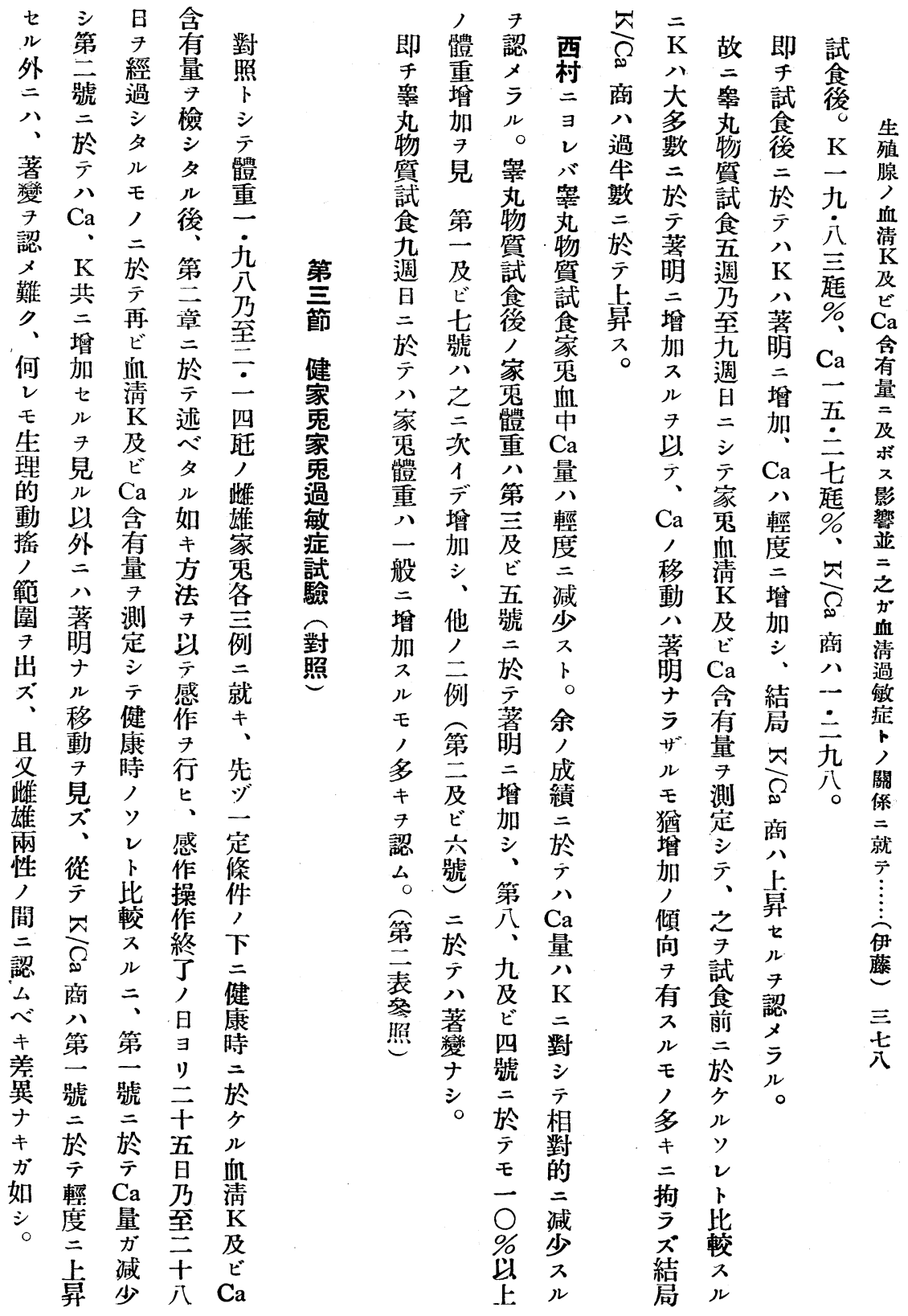




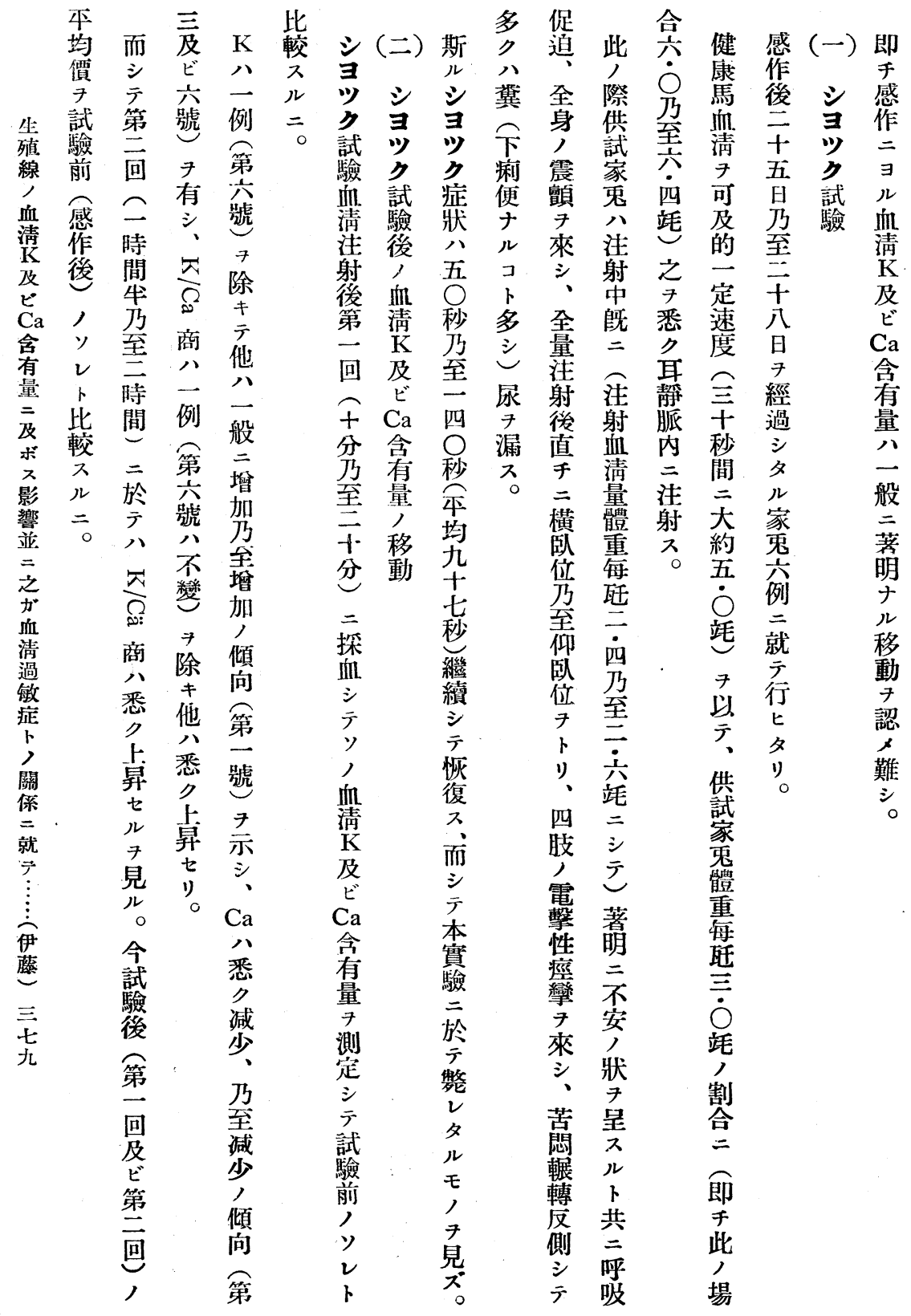




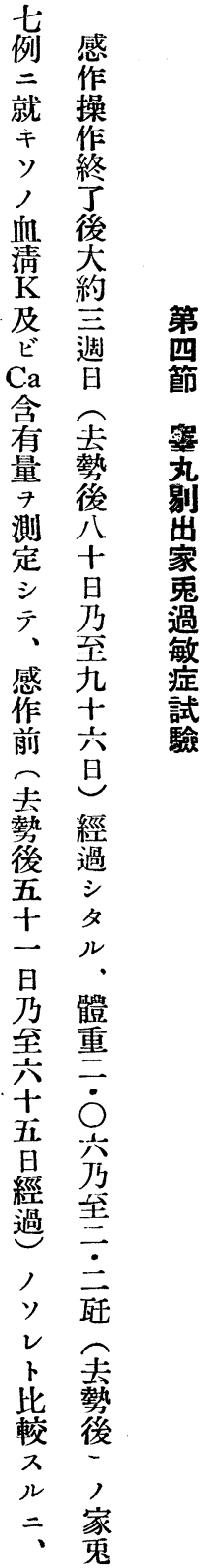

第三表 健康家鬼過敏店試驗

\begin{tabular}{|c|c|c|c|c|c|c|c|}
\hline 番號 & 性 & $\begin{array}{l}\text { 體重 } \\
\text { (互) }\end{array}$ & イオン & 健康時 & 感作後 & 試噞後 I & 試驗後 II \\
\hline \multirow{3}{*}{1} & \multirow{3}{*}{ f } & \multirow{3}{*}{$19 \div 0$} & K & 20.02 & 19.77 & 20.01 & 19.42 \\
\hline & & & $\mathrm{Ca}$ & 15.16 & 14.48 & 13.91 & 14.34 \\
\hline & & & $\mathrm{K} / \mathrm{Ca}$ & 1.32 & 1.365 & 1.438 & 1.354 \\
\hline \multirow{3}{*}{2} & \multirow{3}{*}{$\uparrow$} & \multirow{3}{*}{2100} & $\mathrm{~K}$ & 17.46 & 18.57 & 20.26 & 18.83 \\
\hline & & & $\mathrm{Ca}$ & 14.92 & 15.58 & 14.78 & 14.02 \\
\hline & & & $\mathrm{K} / \mathrm{Ca}$ & 1.17 & 1.191 & 1.364 & 1.343 \\
\hline \multirow{3}{*}{3} & \multirow{3}{*}{ 우 } & \multirow{3}{*}{2070} & $\mathrm{~K}$ & & 19.39 & 20.34 & 20.06 \\
\hline & & & $\mathrm{Ca}$ & 15.20 & 15.41 & 15.11 & 14.06 \\
\hline & & & $\mathrm{K} / \mathrm{Ca}$ & 1.232 & 1.253 & 1.346 & 1.426 \\
\hline \multirow{3}{*}{4} & \multirow{3}{*}{ 우 } & \multirow{3}{*}{1990} & $\mathrm{~K}$ & 18.28 & 18.64 & 20.34 & 20.50 \\
\hline & & & $\mathrm{Ca}$ & 14.62 & 15.04 & 14.58 & 14.06 \\
\hline & & & $\mathrm{K} / \mathrm{Ca}$ & 1.25 & 1.233 & 1.395 & 1.458 \\
\hline \multirow{3}{*}{5} & \multirow{3}{*}{$\hat{\delta}$} & \multirow{3}{*}{2120} & $\mathrm{~K}$ & 16.33 & 16.64 & 18.13 & 17.51 \\
\hline & & & $\mathrm{Ca}$ & 14.16 & 14.27 & 13.74 & 13.12 \\
\hline & & & $\mathrm{K} / \mathrm{Ca}$ & 1.153 & 1.166 & 1.319 & 1.334 \\
\hline \multirow{3}{*}{6} & \multirow{3}{*}{$\uparrow$} & \multirow{3}{*}{2140} & $\mathrm{~K}$ & 18.05 & 18.28 & 18.13 & 18.93 \\
\hline & & & $\mathrm{Ca}$ & 14.18 & 14.48 & 14.36 & 14.16 \\
\hline & & & $\mathrm{K} / \mathrm{Ca}$ & 1.272 & 1.263 & 1.262 & 1.336 \\
\hline \multirow[t]{3}{*}{ 本 } & & & $\mathrm{K}$ & 18.15 & 18.54 & 19.53 & 19.21 \\
\hline & & & $\mathrm{Ca}$ & 14.71 & 14.88 & 14.41 & 13.96 \\
\hline & & & $\mathrm{K} / \mathrm{Ca}$ & 1.232 & 1.246 & 1.355 & 1.376 \\
\hline
\end{tabular}

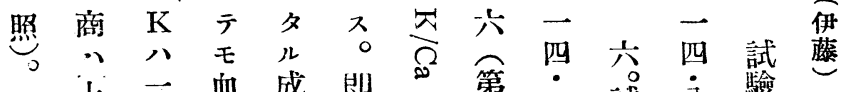

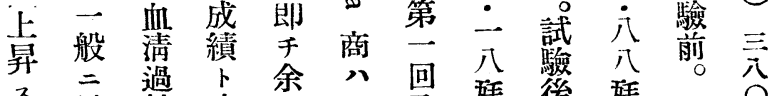

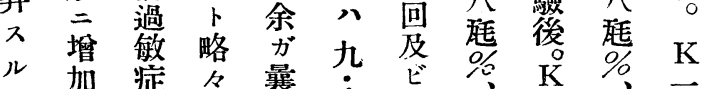
7 加嫣々 暈

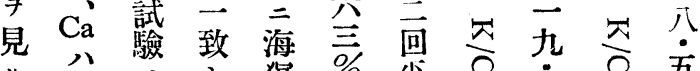

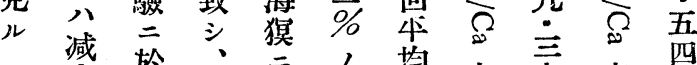

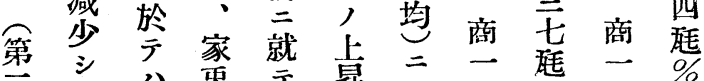

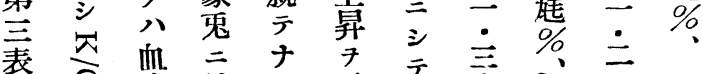
參 清 於 シ 示テ、亲 $\mathrm{Ca}$ 西 $\mathrm{Ca}$ 


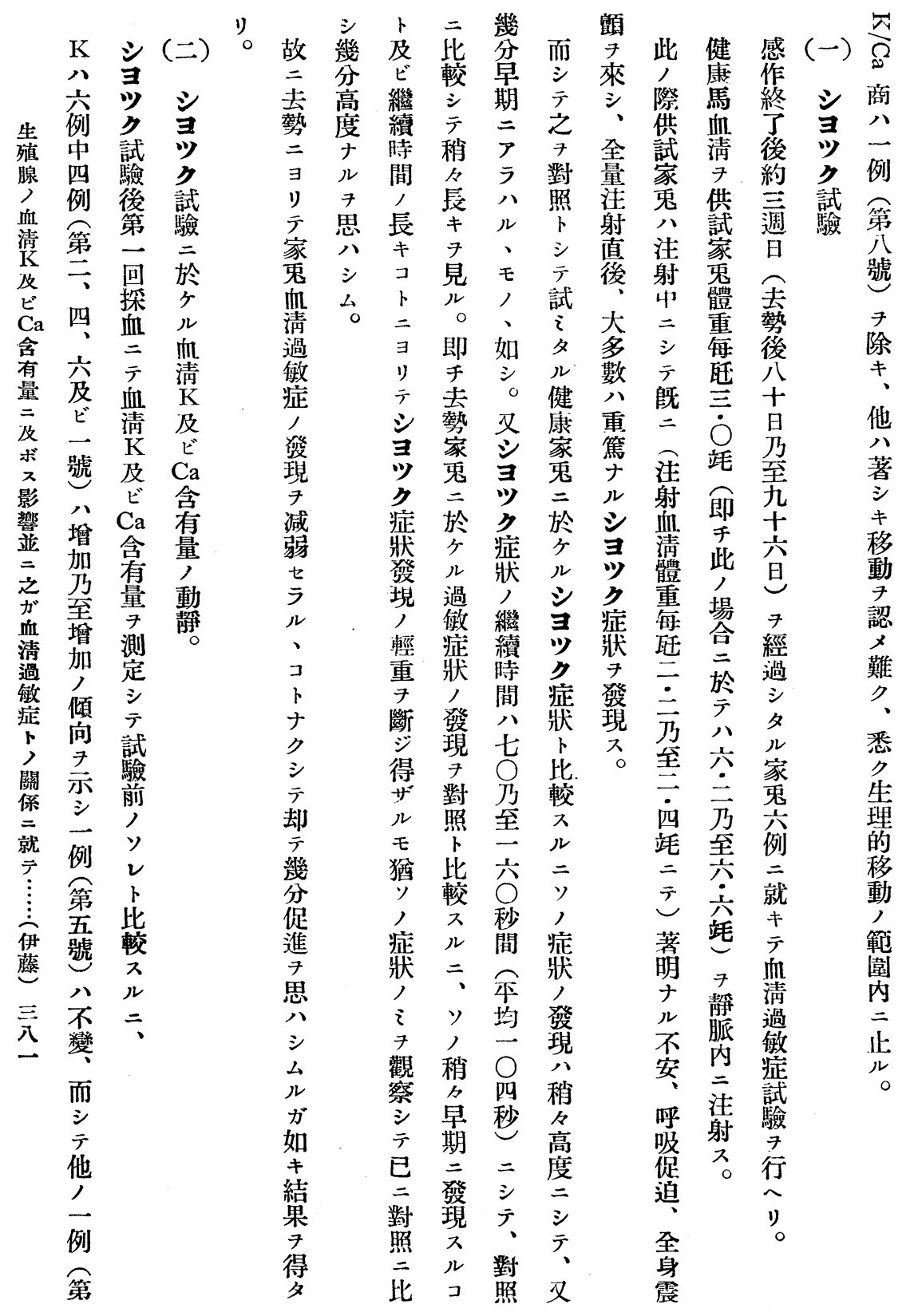




\begin{tabular}{|c|c|c|c|c|c|c|}
\hline & & 第四 & 睪好 & 剠出家鬼 & 過敏跋試 & \\
\hline 䡴 & 番號 & イオン & 去勢後 & 感作後 & 試驗後 I & 試鐱後 \\
\hline テ & & K & 15.76 & 16.11 & 16.59 & 14.96 \\
\hline 稍 & 1 & $\mathrm{Ca}$ & 15:76 & 16.08 & 15.86 & 14.80 \\
\hline & & $\mathrm{K} / \mathrm{Ca}$ & 1.0 & 1.0 & 1.046 & 1.011 \\
\hline 明 & & $\mathrm{K}$ & 16.33 & 16.12 & 18.29 & 17.59 \\
\hline נ & 2 & $\mathrm{Ca}$ & 15.54 & 15.64 & 15.76 & 15.00 \\
\hline & & $\mathrm{K} / \mathrm{Ga}$ & 1.05 & 1.016 & 1.159 & 1.169 \\
\hline & & $\mathrm{K}$ & 16.61 & 15.83 & 18.29 & 17.13 \\
\hline 第 & 3 & $\mathrm{Ca}$ & 16.00 & 15.86 & 15.76 & 14.84 \\
\hline 四 & & $\mathrm{K} / \mathrm{Ca}$ & 1.038 & 1.0 & 1.159 & 1.154 \\
\hline 參 & & $\mathrm{K}$ & 20.59 & 17.87 & 18.96 & 17.61 \\
\hline 照 & 4 & $\mathrm{Ca}$ & 16.10 & 14.88 & 14.46 & 13.70 \\
\hline & & $\mathrm{K} / \mathrm{Ca}$ & 1.275 & 1.202 & 1.304 & 1.285 \\
\hline & & $\mathrm{K}$ & 16.47 & 17.04 & 17.13 & 16.81 \\
\hline & 5 & $\mathrm{Ca}$ & 15.10 & 15.54 & 15.22 & 14.57 \\
\hline & & $\mathrm{K} / \mathrm{Ca}$ & 1.09 & 1.096 & 1.125 & 1.153 \\
\hline & & $\mathrm{K}$ & 17.46 & 17.31 & 19.70 & 17.81 \\
\hline & 6 & $\mathrm{Ca}$ & 16.00 & 16.00 & 15.11 & 13.69 \\
\hline & & $\mathrm{K} / \mathrm{Ca}$ & 1.09 & 1.07 & 1.307 & 1.303 \\
\hline & & $\mathrm{K}$ & 14.91 & 18.60 & 18.18 & 17.16 \\
\hline & 7 & $\mathrm{Ca}$ & 15.10 & 15.06 & 12.48 & 12.16 \\
\hline & & $\mathrm{K} / \mathrm{Ca}$ & $0.9 ; 7$ & 1.235 & 1.456 & 1.411 \\
\hline & 本 & $\mathrm{K}$ & 16.58 & 16.93 & 18.16 & 17.01 \\
\hline & & $\mathrm{Ca}$ & 15.64 & 15.58 & 14.80 & 14.10 \\
\hline & 均 & $\mathrm{K} / \mathrm{Ca}$ & 1.059 & 1.088 & 1.233 & 1.212 \\
\hline
\end{tabular}

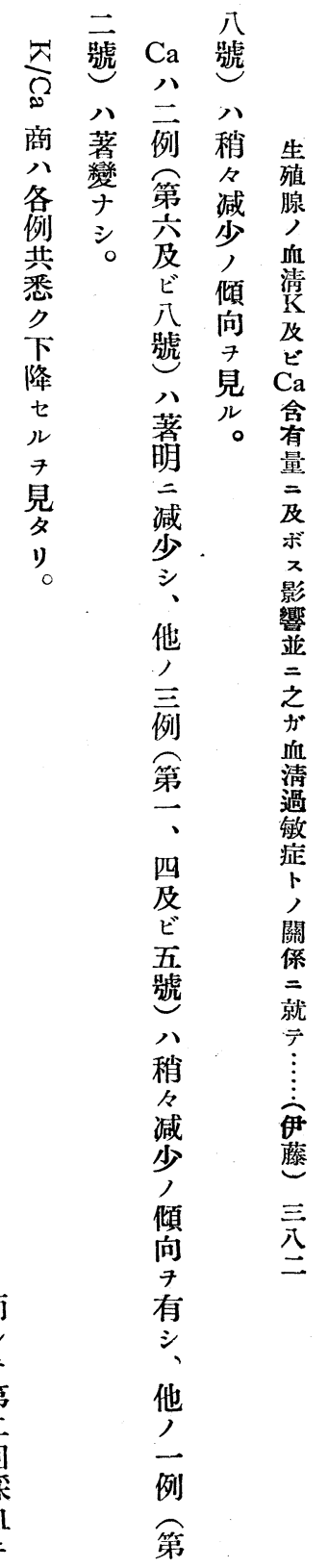

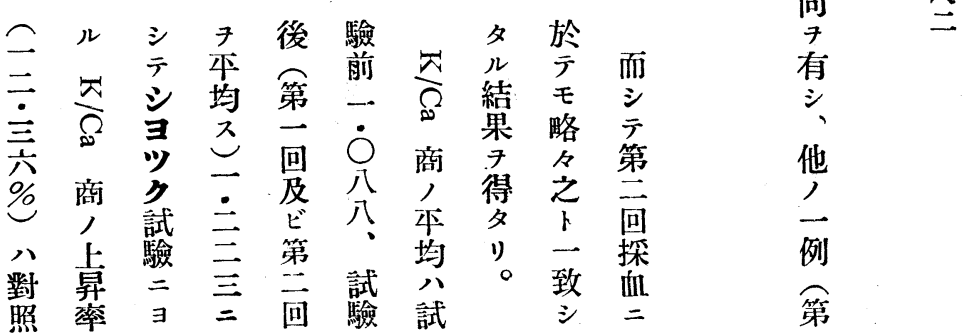




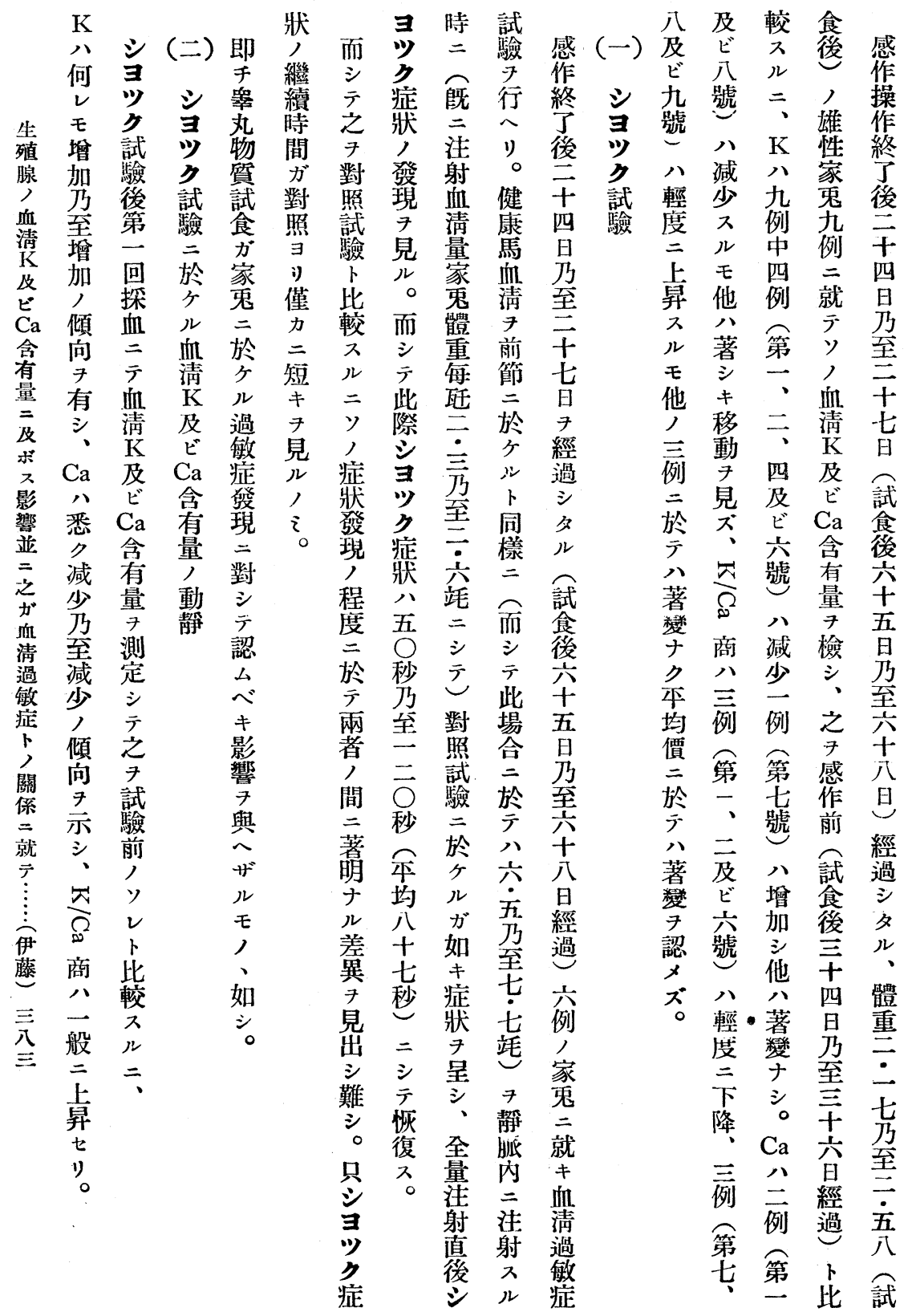




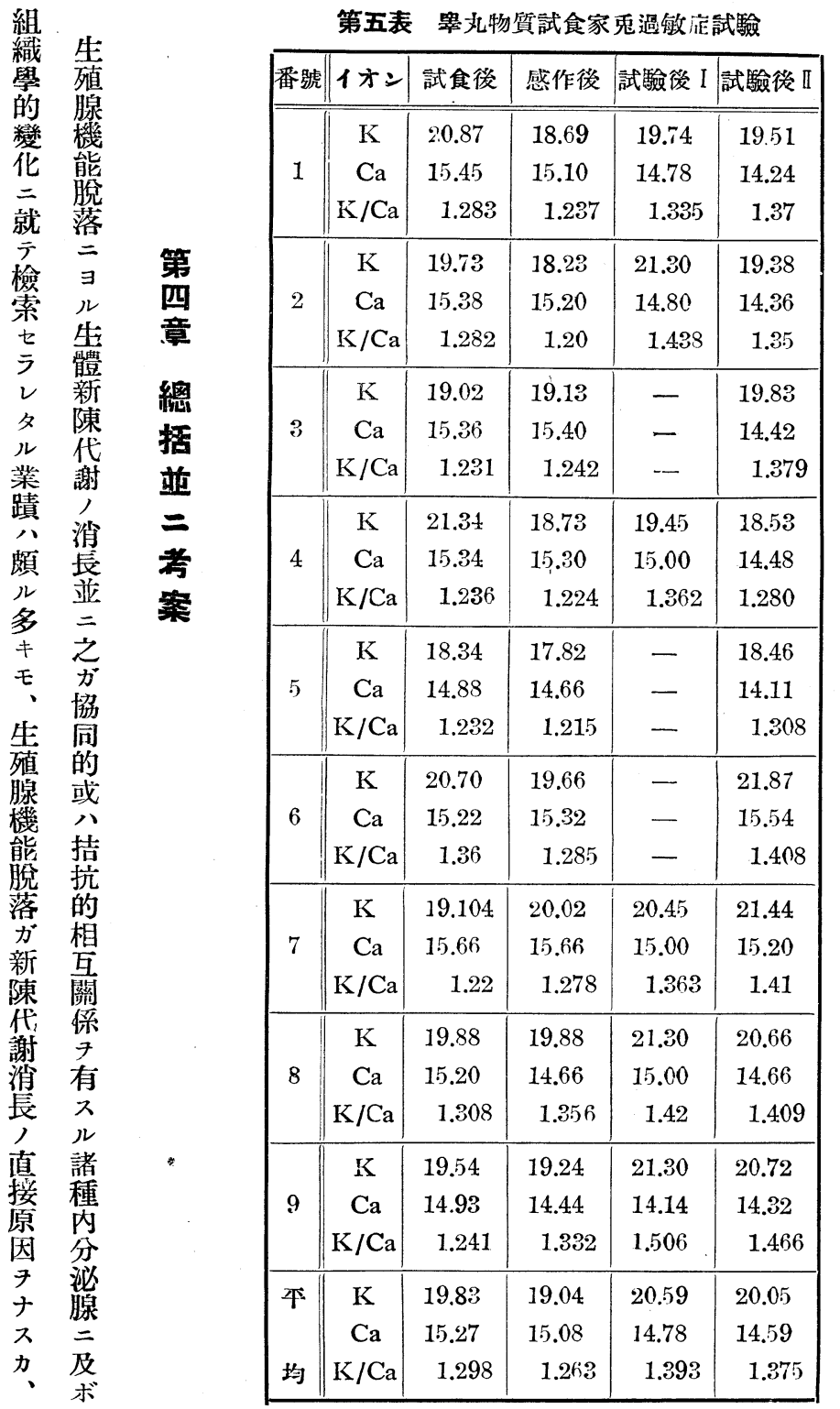

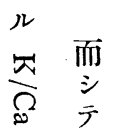

商 式 堹

点商血

率尔渻

九均范

五 試 Ca

八 噞 弇

八 整夏

照 三 标

亲 影

比 三

較試

テ 䲓 之

y 後

閔算

間 第 過

盖敏

兾莫;

䛠第 關

諗第保

難 面就

染等

八佇

一 藤

齐

四分

츨

テ

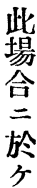









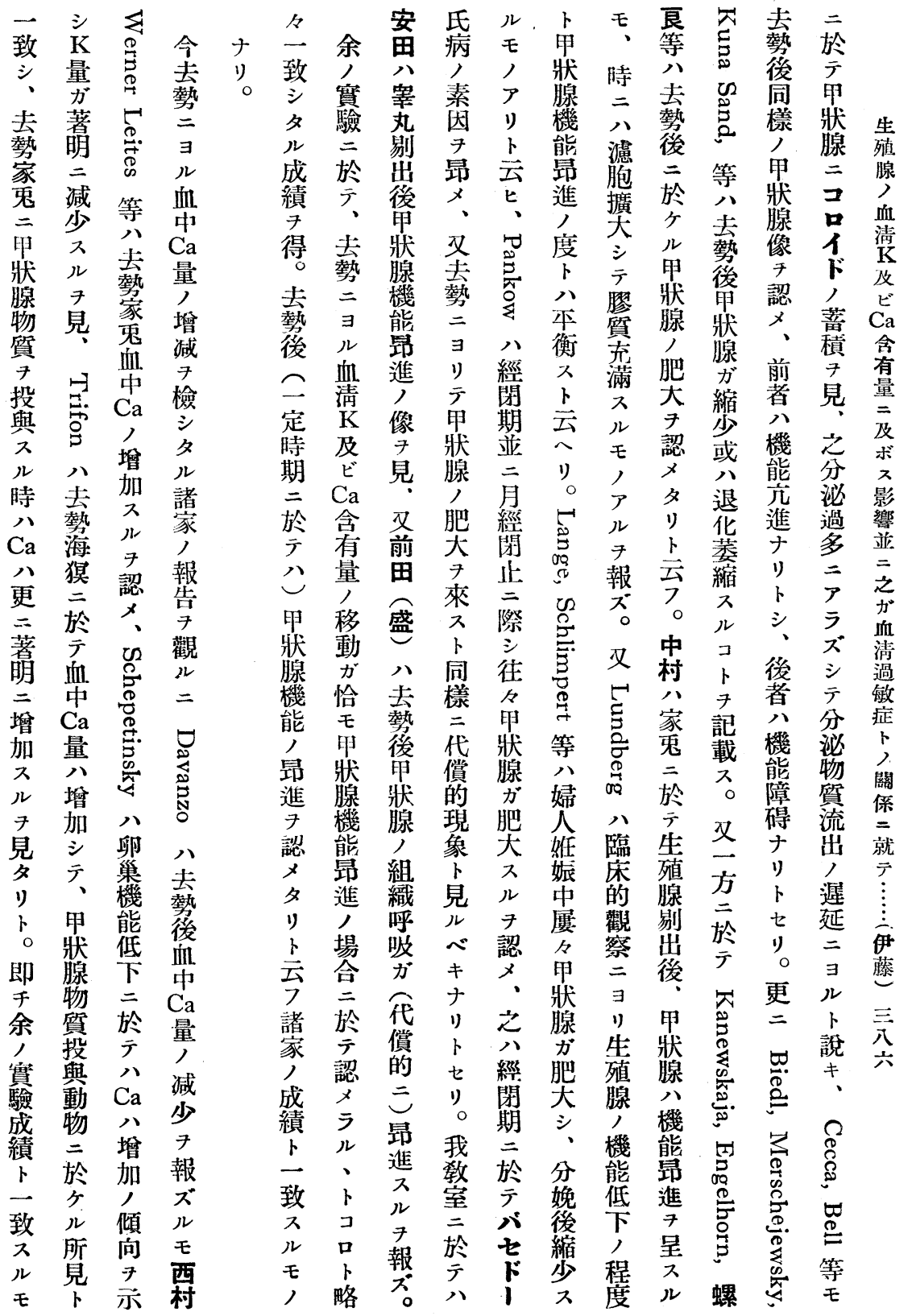




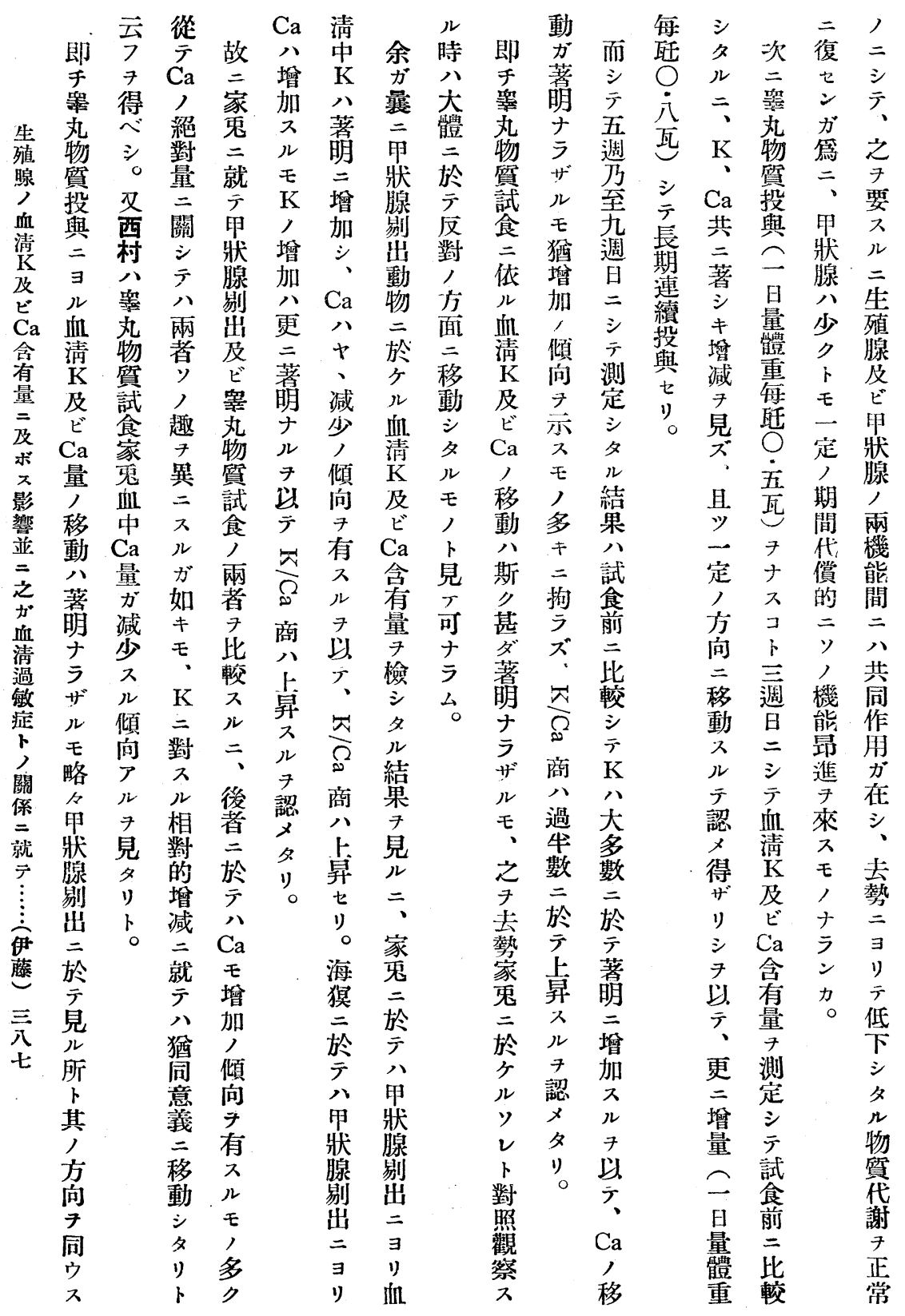




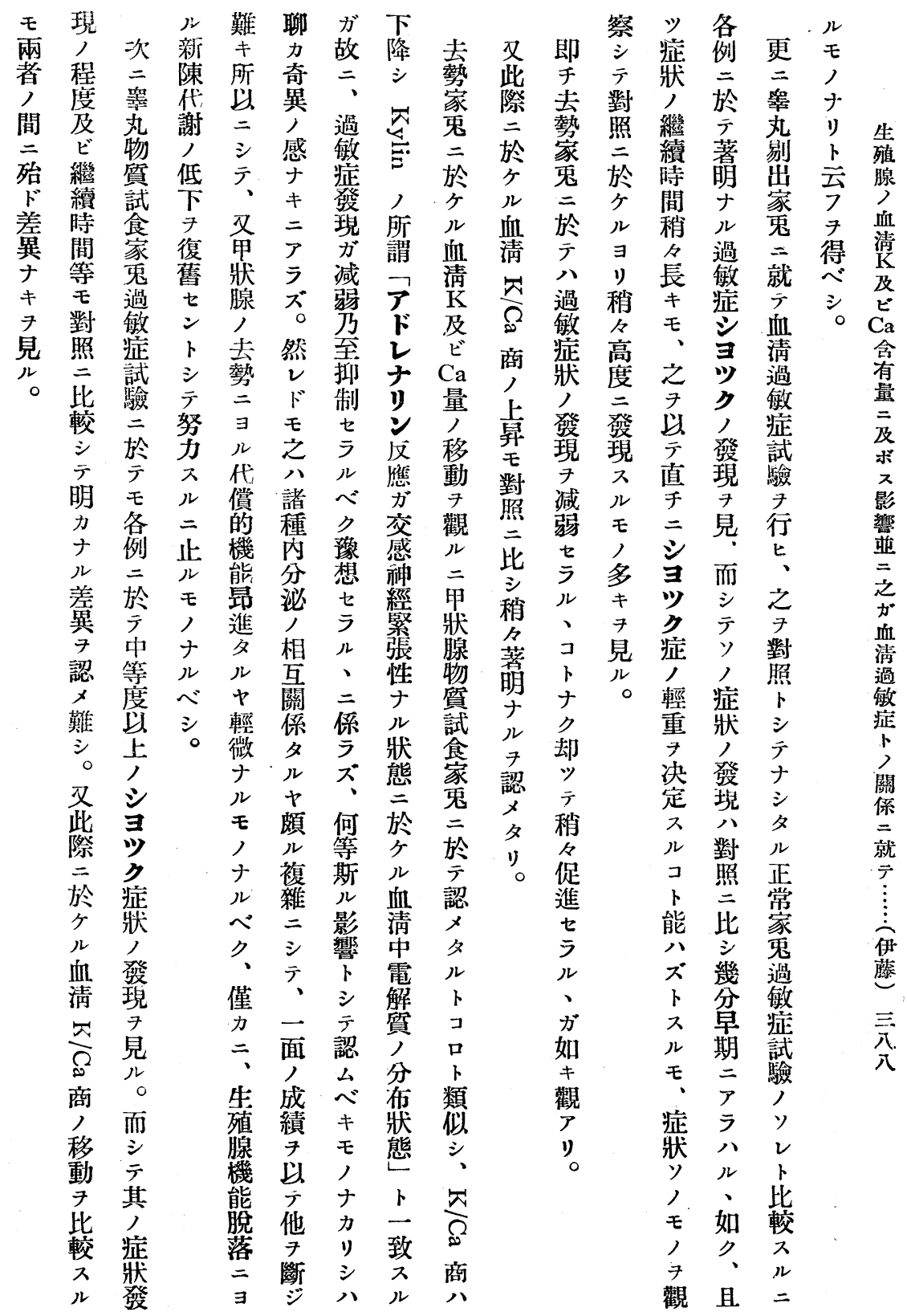




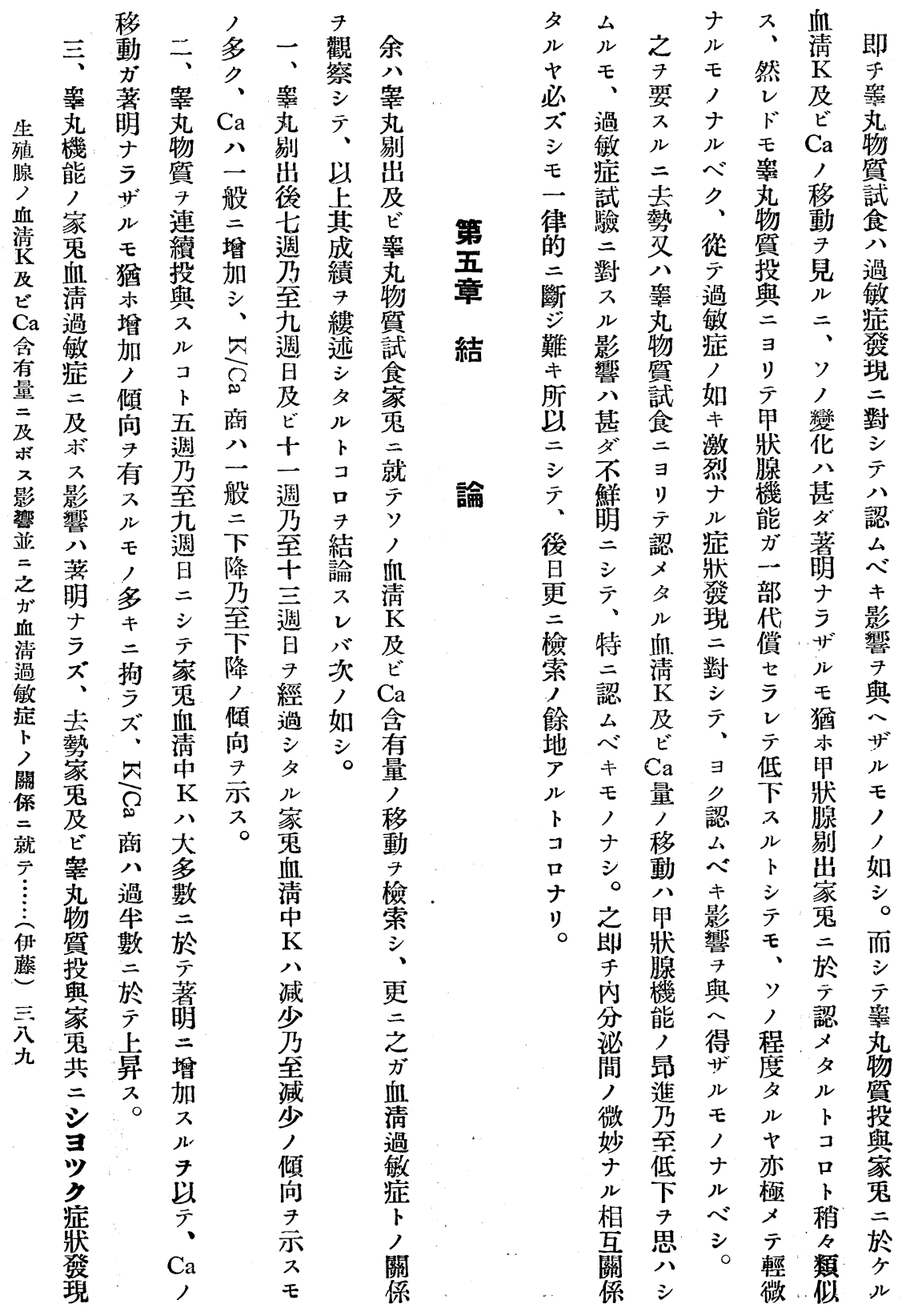



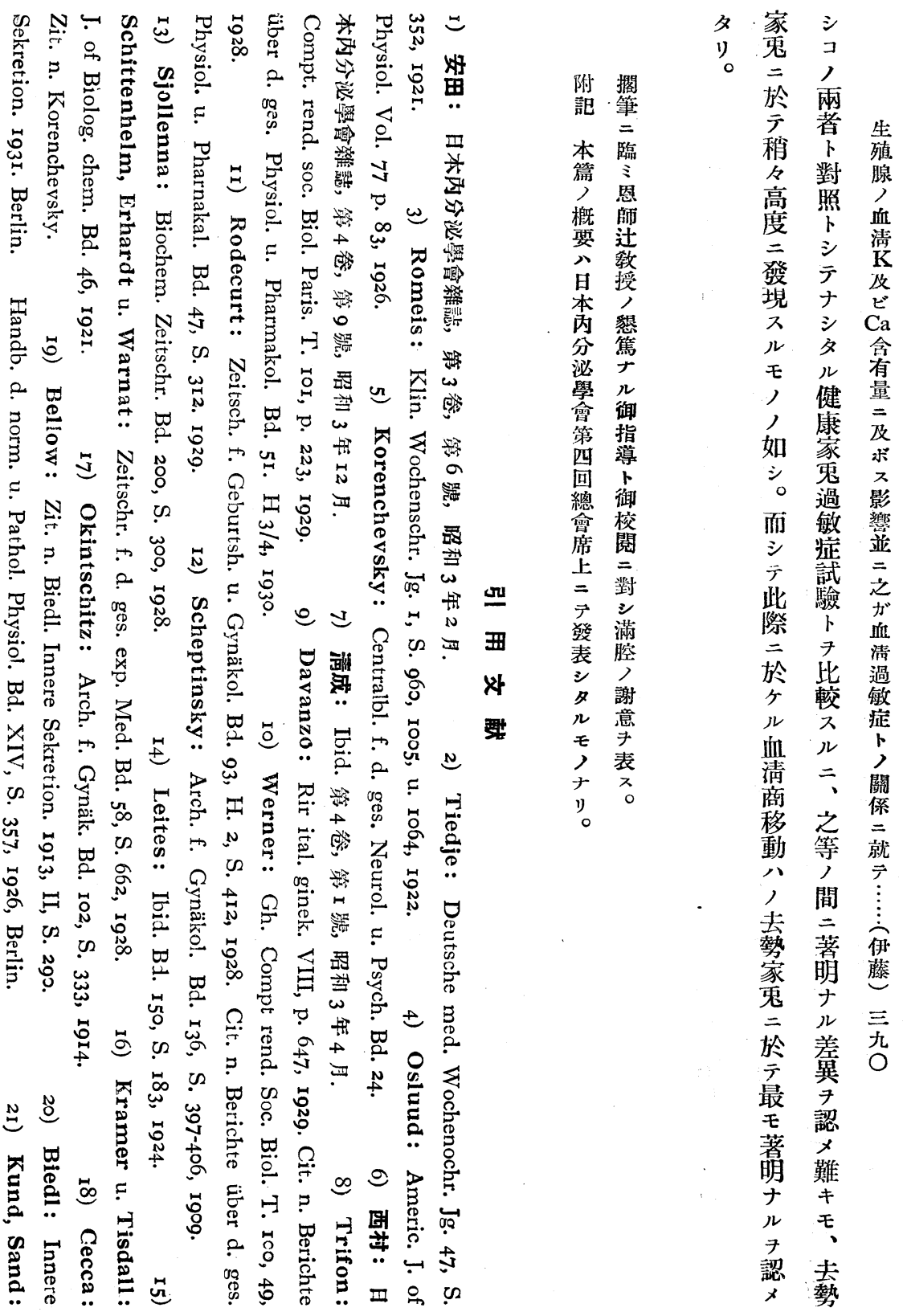


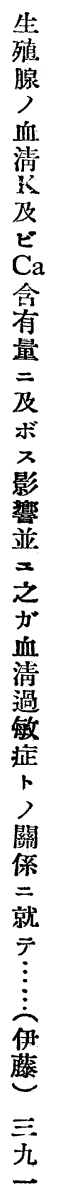

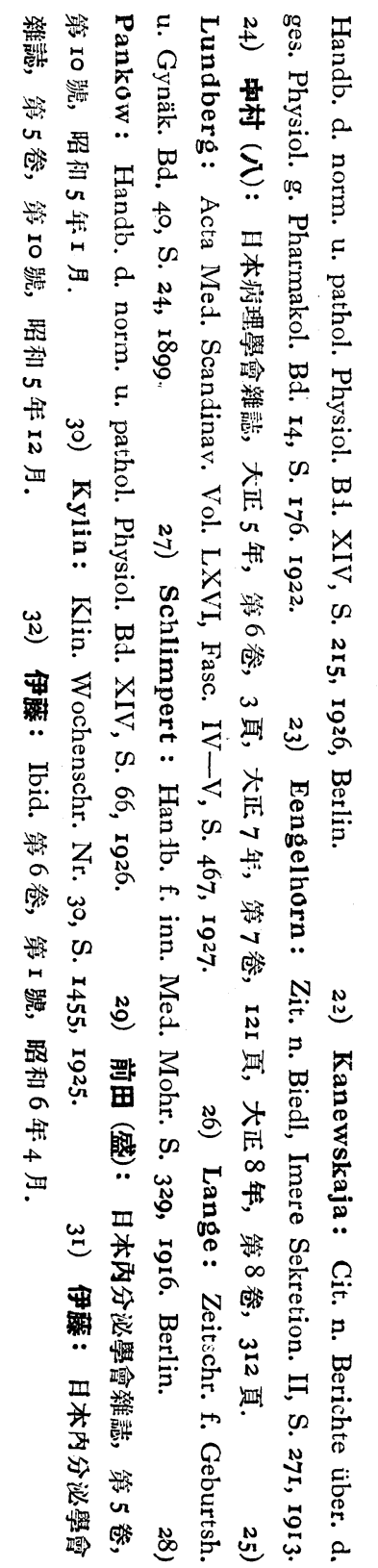


Zunahme.

3. Nach diesen Ergebnissen nimmt der Verf. an, dass Ovariumparenchym und Corpus luteum bezüglich des Jodgehalts der Schilddrüse in antagonistischem Verhältnis zueinander stehen.

4. Bei Fütterung mit Hoden neigt wie bei der mit Ovariumparenchym der Jodgehalt der Schilddrüse zur Abnahme, doch nicht so deutlich wie bei der letzteren.

5. Durch Exstirpation der Hoden nimmt das Gewicht der Schilddrüse ab, der Jodgehalt jedoch deutlich zu.

6. Jurch Ovariumexstirpation fällt das Gewicht der Schilddrüse und steigt der Jodgehalt mässig an, doch nicht so deutlich wie bei der Hodenexstirpation.

7. Aus der Verschiebung des Jodgehalts der Schilddrüse lässt sich der Schluss ziehen, dass die Sexualdrüse auf die Schilddrüsenfunktion beschleunigend wirkt, das Corpus luteum dagegen hemmend.

(Autoreferat)

\section{Ueber den Einfluss der Geschlechtsdrüsen auf den Kalium- und Calciumgehalt im Blutserum und auf künstlich erzeugte Serumanaphylaxie. \\ I. Mitteilung : Ueber den Einfluss der Hoden auf den Kalium- und Calciumgehalt im Blutserum und auf künstlich erzeugte Serumanaphylaxie.}

Von

Dr. S. Itoh.

(Aus der I med. Klinik der Kaiserl. Univers. zu Kyoto in Japan. Direktor: Prof. Dr. K. Tsuji.)

An erwachsenen männlichen Kaninchen exstirpierte der Verfasser die Hoden oder fütterte über 5 Wochen lang mit 
Hodensubstanz (0.5-0.8 g trockener Rinderhodensubstanz per Kilogramm Körpergewicht pro die). Darauf untersuchte er die Verschiebung des $\mathrm{K}$ - und Ca-gehalts im Blutserum und studierte weiter den Einfluss des Hodenhormons auf künstlich erzeugte Serumanaphylaxie.

Die Resultate waren die folgenden:-

I. Der K-gehalt im Blutserum nahm meistens 7-I3 Wochen nach der Kastration $\mathrm{ab}$, während der Ca-gehalt im allgemeinen zunahm, infolgedessen der K/Ca-Quotient im Blutserum fiel oder zum Fallen neigte.

2. Bei den $5-7$ Wochen lang mit Hodensubstanz gef ütterten Kaninchen stieg der K-gehalt meistens. Auch der Ca-gehalt neigte mehr oder weniger zur Steigerung. Doch die Zunahme des K-gehalts war auffallender, wodurch der K/Ca-Quotient im Blutserum meistens stieg.

3. Der Einfluss der Hodenhormone auf künstlich erzeugte Serumanaphylaxie war undeutlich. Die Kastration oder Hodensubstanzfütterung schien keinen auffallenden Einfluss auf die Entstehung des Shocks auszuüben. Bei beiden Fällen trat die anaphylaktische Shockerscheinung fast ebenso deutlich auf wie bei den gesunden Kaninchen, welche zur Kontrolle benutzt wurden. Doch scheint die Shockerscheinung bei den kastrierten Kaninchen noch etwas hochgradiger zu sein, jedoch nicht weiter auffallend. Die Zunahme des K/Ca-Quotienten im Blutserum war nach dem Shockversuch beim kastrierten Kaninchen am stärksten.

(Autoreferat)

\section{Ueber den Einfluss der Geschlechtsdrüsen auf den Kalium- und Calciumgehalt im Blutserum und auf künstlich erzeugte Serumanaphylaxie.}

